\title{
Approach for Acquiring Computer Systems to Satisfy Mission Capabilities
}

\author{
Glenn Tolentino \\ Command and Control Department \\ Space and Naval Warfare Systems \\ Center Pacific \\ San Diego, CA, USA
}

\author{
Dr. Jeff Tian \\ Computer Science and Engineering \\ Department \\ Southern Methodist University \\ Dallas, TX, USA
}

\author{
Dr. Jerrell Stracener \\ Engineering Management, \\ Information, and Systems \\ Department \\ Southern Methodist University \\ Dallas, TX, USA
}

\begin{abstract}
Defense Computer Systems developed and maintained over the years has resulted in thousands of disparate, compartmented, focused, and mission driven systems that are utilized daily for deliberate and crisis mission planning activities. The defense acquisition community is responsible for the development and sustainment of these systems over the course of its systems engineering lifecycle from conception, utilization, and eventually the decommissioning of these systems. While missions are being planned, and satisfied by existing computer systems, there are new missions being proposed which cannot be satisfied by a single existing computer system capability. Therefore, this raises the question whether a Networked Computer System (NCS) using combinations of existing and developmental computer systems is preferred in order to satisfy new capability requirements. This paper explores an approach in identifying a preferred NCS solution and determining the effectiveness in satisfying a mission.
\end{abstract}

Keywords-Systems Integration; Systems Development; Systems Reliability; Software Systems; Systems Engineering; Lifecycle Cost

\section{INTRODUCTION}

The United States Department of Defense (DoD) acquisition community applies systems rigor throughout the lifecycle phases of a system. At the end of the lifecycle, the sustainment phase provides the DoD with a system to address the needs of the warfighters [1]. During the sustainment phase, the system is maintained until it is deemed operationally unusable or supported. At the end of a system's operational use, it is eventually decommissioned or retired from service. However, due to budget cuts and decline of defense spending, there is no follow up funding to replace the legacy system. Therefore, with no plans for system replacement, the legacy system is used longer than the planned operational period estimated. In this case, with no funding source, the system cannot integrate new technologies to produce new operational system capabilities, making it difficult to evolve the system over time to satisfy both existing and incoming user requirements. This situation makes it a daunting task to sustain and upgrade functionalities for the same system capability. Therefore, the legacy system capability is sustained over a period of time until a new developed system can satisfy the legacy system's capability.

One major concern that emerges due to the budget cuts to the $\mathrm{DoD}$ is the challenge of satisfying requirements for the warfighters needing a new operational system capability. In the past, the obvious solution was to develop a completely new system to satisfy the new system capability. However, defense spending has decreased over time and the acquisition community must now seek innovative ways to satisfy the new systems capabilities needed in order to accomplish the DoD operational mission. In a simple case, similar legacy systems have been repurposed with some level of integration and limited funding. These systems are often retrofitted to accomplish the mission with some limited capabilities. In an extreme case, a capability may not be able to be satisfied with a single legacy system. At this point, the first consideration is to develop a completely new system, which is often not feasible due to budgetary constraints. However, one approach is to determine whether a combination of the existing legacy systems capabilities can satisfy a new capability.

There has a been a number of work in the area of reuse of DoD legacy systems. However, there is one area of research that is considered to be deficient or inadequately research in determining an effective reuse of systems. As presented in a study presented in the Defense Research Journal (DRJ) [4], "Regardless of all of the theoretical work, tools, and cost models available, one key area remains inadequately researched: how program managers should determine whether or not they will efficiently and effectively reuse hardware and software legacy systems based on cost, schedule, risk, operations and maintenance (O\&M), and performance”.

This paper presents an approach for selecting a combination of existing systems for emerging requirements to satisfy new capabilities while reusing existing and proven capabilities. Decision attributes will be considered in selecting computer systems and measuring the networked computer system's effectiveness to accomplish the mission. This proposed approach will enable system stakeholders in making critical well informed decisions to address continuing evolution of operational missions, multidimensional threats, budget constraints, and expanding technologies.

\section{RELATED WORK}

A survey was performed based on the DoD need for an operational system capability that can satisfy a defense mission, and specifically to determine if the capability requires a group of systems to be developed into a single NCS solution. Since the DoD invests a great deal of resources into the 
acquisition and management of these computer systems, these systems are often developed with the goals of reusing and ensuring interoperability and scalability with other systems. By doing so, it will benefit the development process of reusing existing capabilities by systems that are currently in development. This process leads to systems that are well integrated, however, it may not satisfy the overall defense operational mission objectives (see Fig. 1). The purpose of this approach in acquiring computer systems capability is to be able select a preferred NCS solution and measure the effectiveness of these developed and integrated computer systems with the end goal of mission success.

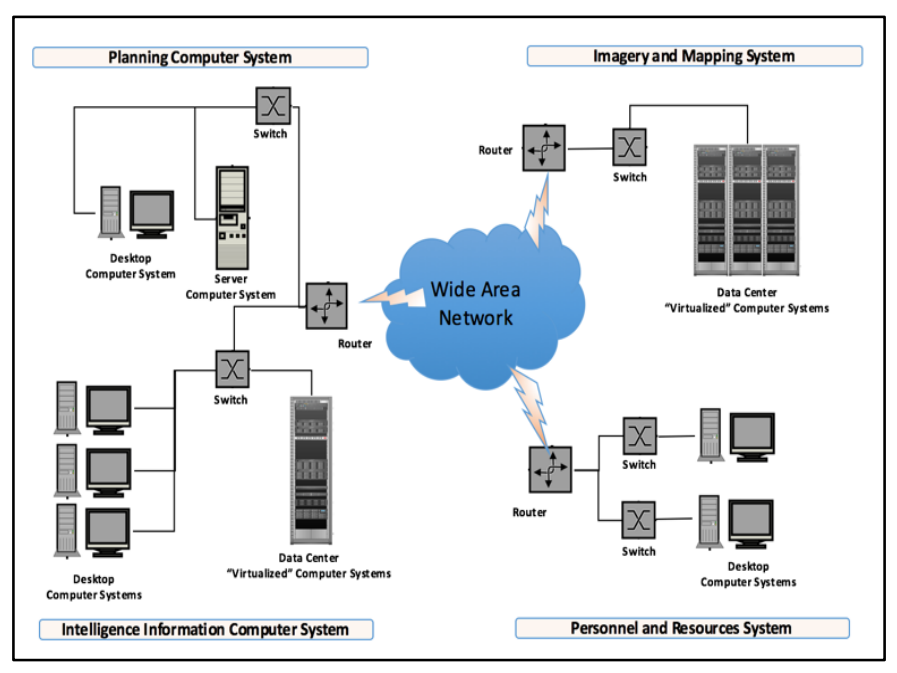

Fig. 1. Notional Defense Related Networked Computer System

The United States DoD acquisition community manages and executes varying types of systems development with one area being computer systems. Most, if not all, of the systems that can be characterized in the cyber domain would be considered computer systems: computers connected by computer networking [9]. Therefore, the research performed addresses a critical need for the defense acquisition community since minimum work is considered in the area of dynamic continuous mission planning in selecting a networked computer system, providing a unique capability to satisfy a defense mission. The benefit of being able to select the preferred NCSs will allow high-level decision makers to make a determination quickly in satisfying both critical and noncritical missions in response to safe guard the United States national security.

\section{OVERVIEW}

As part of this approach, there are a number of steps that must be accomplished in order to select computer systems in developing the NCS solution and measuring the solution's effectiveness. The proposed approached is summarized in the following (see Fig. 2):

\begin{tabular}{|c|c|}
\hline \multicolumn{2}{|r|}{ Phase 1} \\
\hline \multicolumn{2}{|r|}{ Selecting Computer Systems in Developing an NCS Solution } \\
\hline Step 1 & Describe the NCS Mission \\
\hline Step 2 & $\begin{array}{l}\text { Identify computer systems with capabilities to satisfy mission } \\
\text { required functionalities }\end{array}$ \\
\hline Step 3 & $\begin{array}{l}\text { Determine computer systems for NCS consideration } \\
\text { - System capability availability } \\
\text { - } \text { Capability readiness } \\
\text { - Acquisition time } \\
\text { - Acquisition cost } \\
\end{array}$ \\
\hline Step 4 & Determine NCS solution to satisfy mission \\
\hline \multicolumn{2}{|r|}{ Phase 2} \\
\hline \multicolumn{2}{|r|}{ Determining the Measure of Effectiveness of the NCS solution } \\
\hline Step 1 & $\begin{array}{c}\text { Evaluate NCS solution based on decision attributes: } \\
\text { - Capability sustainment definition and estimation } \\
\text { - } \text { Lifsion reliability definition and estimation } \\
\text {. }\end{array}$ \\
\hline Step 2 & Determine measure of effectiveness based on decision attributes \\
\hline
\end{tabular}

Fig. 2. Acquiring Computer Systems Approach

\section{SELECTING COMPUTER SYSTEMS}

This first phase focuses on developing an NCS solution for a given mission based on mission requirements and objectives. This phase will address the development of an NCS solution based on existing computer systems that are either already operational or currently being developed with a known time for capability readiness and acquisition. As the initial step during the NCS mission description, it describes the intended overall mission or missions of the NCS. This would be the high overview activity on what is to be performed with specific mission objectives. These mission objectives can be translated as a set of activities required to be performed to achieve mission success. In addition, it can be characterized as the mission profile which eventually translates to specific capabilities required by the NCS in order to satisfy each of the mission objectives.

Once the NCS mission is properly characterized, computers systems are identified that will satisfy the mission required capabilities. During this step, each of the capabilities required for the NCS solution is identified. Once all of the capabilities are identified, the capabilities objectives are established along with high level capabilities requirements to satisfy the objectives. The capability requirements are then used to determine a similar match with initial candidate computer systems in being able to satisfy each of their requirements. This provides a list of computer systems in satisfying each of the capabilities required for the mission. Once there is a number of computer systems assigned to each of the capabilities, the next process provides a means in selecting the systems based on decision attributes with respect to system capability availability, capability readiness, acquisition time, and acquisition cost (see Fig. 3). 


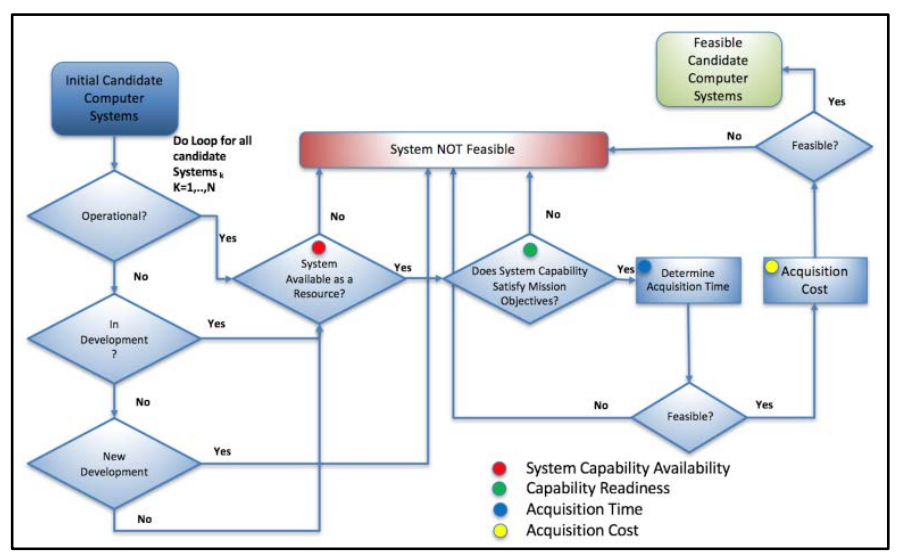

Fig. 3. Approach for Determining Feasible Candidate Computer Systems

This selection process provides a library list of computer systems for each of the capabilities required for the NCS solution. The library list of computer systems will be available as part of a down select process in identifying potential computer system candidates to be considered into the NCS solution. The identification process will utilize a process at the discretion of the stakeholder to determine which computer systems are the "best" candidates in accomplishing the NCS capability objectives. This approach will enable the stakeholders to be able to provide a level of balance between objective and subjective decision process making on selecting the computer systems as a component of the preferred NCS solution.

\section{Determining the Measure of EfFectiveness of THE NCS SOLUTION}

The purpose of the second phase is to evaluate the NCS solution based on the decision attributes in quantifying the NCS solution's effectiveness. This phase will evaluate the NCS solution based on the decision attributes selected (capability sustainment, lifecycle cost, and mission reliability) and measure the effectiveness based on estimations.

The NCS solution will be evaluated based on decision attributes that is related to the Measure of Effectiveness (MOE) construct. In terms of MOE, the NCS solution will consider effectiveness in capability sustainment, mission reliability, and capability lifecycle cost. Each of the decision attributes will be quantitatively estimated and analyzed in determining the measures of effectiveness of the NCS solution that could further be analyzed and evaluated.

\section{A. Capability Sustainment}

Capability Sustainment translated as basic reliability is considered to be a measure of sustainability and operations and support of a system. As defined in MIL-STD-785B [2], "the measures of basic reliability such as Mean-Time-BetweenFailures (MTBF) include all item life units (not just mission time) and all failures within the item (not just mission-critical failures of the item itself)". Basic reliability requirements apply to all items of the system.

In terms of computer systems, the two primary components can affect basic reliability are software and hardware. The interrelationship between hardware and software is a primary driver that can affect the overall reliability of the computer system. The hardware's reliability would consist of all hardware elements of the system in terms of failure that are assessed based on failure rates of the hardware configuration items [5]. Similarly, software reliability can also be characterized in terms of the number of software components and its' reliability based on the number of software failures that occur over time. As part of the informed decision making process, both hardware and software reliability and their dependencies would have to be mathematically formulated in order to estimate and calculate the overall reliability of the system.

\section{B. Mission Reliability}

Mission Reliability is defined as the estimate of the probability the NCS will perform its required functions during the mission over some time period. This definition is based on the assumption that all mission essential items are ready and operational at the start of the mission. Furthermore, Mission Reliability is a system level reliability metric that is a function of: (1) the mission definition in terms of mission essential functions by mission phase and (2) the configuration and failure rates of the NCS essential items by mission phase. The mission must be defined and described in terms of the time duration of each phase and the functions that must be accomplished for the NCS's mission success. The assurance of Mission Reliability can be attributed to systems with increased levels of redundancies and failovers. However, increasing the probability of mission success by improving the Mission Reliability affects Basic Reliability in the form of increased logistics overhead to include support, maintenance, and costs.

\section{Lifecycle Cost}

Lifecycle Cost is one of the requirements in the development of systems that are managed and operated by the DoD [11]. Systems developed within the defense acquisition model follows a cost model to support the affordability between all the phases of a system's lifecycle to include material solution analysis, technology development, engineering and manufacturing development, production and deployment, operation and support [3]. It is important to know the program's cost at particular intervals, in order to ensure that adequate funding is available to execute the program according to plan [8]. "Affordability must be a performance consideration from beginning throughout the lifecycle" [6]. Similarly, the NCS solution will also consider a cost model as a measure of affordability in support of the NCS lifecycle (Planning, Acquisition, Development, Operations and Support, and Decommission) to satisfy a mission.

Since the NCS solution will only be acquiring existing systems that is in development or systems that have already achieved their initial operating capabilities, the NCS solution will support two cost model components; cost model for each of the constituent computer systems and cost model for the NCS solution [3]. The first component is the costs associated in acquiring and engineering the computer systems specifically in developing, integrating, testing, and deploying. These are costs drivers that involves engineering efforts for each of the computer systems that are part of the NCS solution. The second component is the costs associated in managing, 
utilizing, maintaining, and supporting the NCS during its operational lifecycle. The cost is a reoccurring costs throughout the NCS lifecycle for as long as the solution is utilized by the operators.

The cost structure and its elements are cost drivers in developing and sustaining a NCS solution throughout its lifecycle. These cost drivers can be categorized by the lifecycle phases of a NCS solution in the following cost structure elements table:

TABLE I. LIFECYCLE COST ELEMENTS

\begin{tabular}{|c|c|c|}
\hline $\begin{array}{l}\text { Phase } \\
\text { Number }\end{array}$ & Life Cycle Phase & Cost Elements Description \\
\hline 1 & Planning & $\begin{array}{l}\text { Engineering effort cost based on the NCS solution design } \\
\text { with respect to the mission, mission objectives, and } \\
\text { mission requirements }\end{array}$ \\
\hline 2 & Acquisition & $\begin{array}{l}\text { - Cost of Acquiring the computer systems required based on } \\
\text { NCS solution design }\end{array}$ \\
\hline 3 & Development & $\begin{array}{l}\text { - Cost of computer systems compliancy with the NCS } \\
\text { architecture to include development, integration, testing, } \\
\text { and deployment } \\
\text { - ost of computer systems integration into the NCS } \\
\text { architecture to include testing and deployment }\end{array}$ \\
\hline 4 & $\begin{array}{l}\text { Operations and } \\
\text { Support }\end{array}$ & $\begin{array}{l}\text { - Cost of managing, operating, sustaining, and supporting } \\
\text { the NCS solution }\end{array}$ \\
\hline 5 & Decommission & - Cost of de-installation of the NCS solution \\
\hline
\end{tabular}

\section{APPROACH APPLICATION SUMMARY}

The U.S. military conducts search and rescue (SAR) operations on a regular basis. In a SAR situation, personnel search for missing people in dangerous situations, and when those people are found, they are then extracted from harm's way and brought back to safety. In addition to U.S. military SAR operations, SAR missions are also performed daily by other specific experts in the field of law enforcement, fire and safety organizations, and state and federal organizations [7]. However, the threats and dangers associated with SAR performed in a military operation come in the form of hostile forces that may engage in physical attacks, such as enemy fire, that may affect the SAR mission and the safety of all personnel involved therein. In planning a SAR mission in a military operation, it is imperative that the system developing the plan has the correct information delivered to the correct system for some period of time in order to ensure the plan is well defined and executed. During this case study, the NCS used to describe a real-life operation was called SPaAS. The purpose of the SPaAS NCS was to enable the development of plans performed for military SAR operations within challenging, hostile, and austere environments.

Once all the mission capabilities were defined as high level requirements, the next step was to identify computer systems in satisfying those mission capabilities in achieving the overall SPaAS mission. The capability requirements were used to identify existing computer systems that could satisfy the system capability. Each of the constituent computer systems has a set of requirements documented as part of the DoD acquisition process [1]. These computer system requirements were compared with the SPaAS capability requirements to determine if the computer systems were able to satisfy the capability requirements (See Fig. 4).

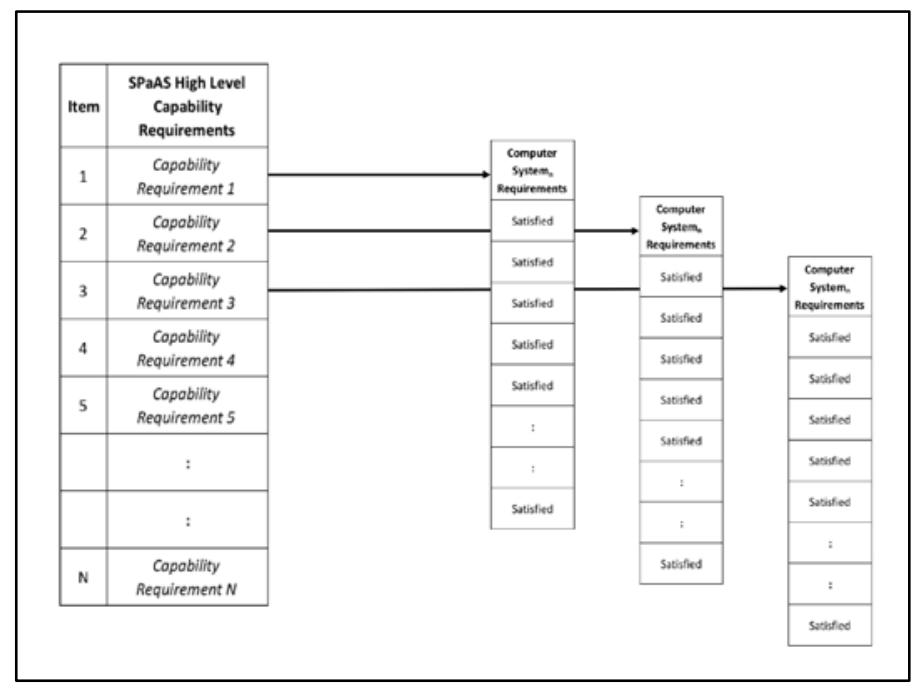

Fig. 4. High Level Capability Requirements Comparison

This process provided a way for each of the SPaAS capability requirements to be able to be compared and matched with available operational computer systems. Each of the computer systems' requirements were compared to the SPaAS capability requirements. If the computer system requirements satisfied the SPaAS capabilities, then the computer systems were included as part of the initial candidate system library list. There may not have been a clear one to one matching of requirements from computer systems to the SPaAS capabilities. However, the NCS SPaAS developer has the flexibility to be able to decide whether the computer system could still be a viable NCS candidate.

The requirements analysis between the computer systems and SPaAS capabilities involved verifying initial candidacy of a computer system to be considered as part of the SPaAS NCS solution. As a first step, those requirements ensured and confirmed that the candidate computer system was able to contribute to satisfying a SPaAS capability. Once it was determined that the computer system was able to provide the capability, the computer system was processed using the Figure 3 flowchart in satisfying additional requirements based on some predetermined decision attributes. The flowchart with the additional decision attributes was used in considering computer systems as part of the selection process to be included in the final library list of systems.

A large number of computer systems were processed through the flowchart, producing a considerable number of candidate computer systems per SPaAS NCS capability. The computer systems that were not successful through the flowchart were deemed as not feasible as candidate systems and therefore were not included in the library list. The outcome of the workflow was a list of candidate systems based on the SPaAS mission capabilities and the confirmation that each of the computer systems in the library list is considered a feasible candidate. Table 2 presents the candidate computer systems library list for each SPaAS capability to be considered as part of the NCS SPaAS solution. 
TABLE II. LIST OF CANDIDATE COMPUTER SYSTEMS

\begin{tabular}{|c|c|c|c|c|c|c|}
\hline NCS Capability & $\begin{array}{l}\text { Candidate Computer } \\
\text { Systems }\end{array}$ & & $\begin{array}{c}\text { System } \\
\text { Capability } \\
\text { Availability }\end{array}$ & $\begin{array}{l}\text { Capability } \\
\text { Readiness }\end{array}$ & $\begin{array}{l}\text { Acquisition } \\
\text { Time }\end{array}$ & $\begin{array}{l}\text { Acquisition } \\
\text { cost }\end{array}$ \\
\hline \multirow{5}{*}{$\begin{array}{l}\text { Joint-Coordinated Mission } \\
\text { Planning System Capability }\end{array}$} & Computer System ${ }_{11}$ & $S_{11}$ & Yes & Yes & Yes & Yes \\
\hline & Computer System $_{12}$ & $S_{12}$ & Yes & Yes & Yes & Yes \\
\hline & Computer System $_{13}$ & $S_{13}$ & Yes & Yes & Yes & Yes \\
\hline & Computer System 14 & $S_{14}$ & Yes & Yes & Yes & Yes \\
\hline & Computer System $_{15}$ & $S_{15}$ & Yes & Yes & Yes & Yes \\
\hline \multirow{5}{*}{$\begin{array}{l}\text { Special Operations Mission } \\
\text { Analysis System Capabilities }\end{array}$} & Computer System ${ }_{21}$ & $S_{21}$ & Yes & Yes & Yes & Yes \\
\hline & Computer System $_{22}$ & $S_{22}$ & Yes & Yes & Yes & Yes \\
\hline & Computer System $_{23}$ & $S_{23}$ & Yes & Yes & Yes & Yes \\
\hline & Computer System $_{24}$ & $S_{24}$ & Yes & Yes & Yes & Yes \\
\hline & ${\text { Computer } \text { System }_{25}}$ & $S_{25}$ & Yes & Yes & Yes & Yes \\
\hline \multirow{5}{*}{$\begin{array}{l}\text { Planning and Effects Based } \\
\text { System Capabilities }\end{array}$} & Computer System ${ }_{31}$ & $S_{31}$ & Yes & Yes & Yes & Yes \\
\hline & Computer System $_{32}$ & $S_{32}$ & Yes & Yes & Yes & Yes \\
\hline & Computer System $_{33}$ & $S_{33}$ & Yes & Yes & Yes & Yes \\
\hline & Computer System $_{34}$ & $S_{34}$ & Yes & Yes & Yes & Yes \\
\hline & ${\text { Computer } \text { System }_{35}}$ & $S_{35}$ & Yes & Yes & Yes & Yes \\
\hline \multirow{5}{*}{$\begin{array}{c}\text { Mission Modeling and } \\
\text { Simulation System Capabilities }\end{array}$} & Computer System $_{41}$ & $S_{41}$ & Yes & Yes & Yes & Yes \\
\hline & Computer System $_{42}$ & $S_{42}$ & Yes & Yes & Yes & Yes \\
\hline & Computer System ${ }_{43}$ & $S_{43}$ & Yes & Yes & Yes & Yes \\
\hline & Computer System 44 & $S_{44}$ & Yes & Yes & Yes & Yes \\
\hline & Computer System 45 & $S_{45}$ & Yes & Yes & Yes & Yes \\
\hline \multirow{5}{*}{$\begin{array}{l}\text { Joint Mission Planning Request } \\
\text { and Approval System } \\
\text { Capabilities }\end{array}$} & Computer System $_{51}$ & $s_{51}$ & Yes & Yes & Yes & Yes \\
\hline & Computer System $_{52}$ & $s_{52}$ & Yes & Yes & Yes & Yes \\
\hline & Computer System $_{53}$ & $S_{53}$ & Yes & Yes & Yes & Yes \\
\hline & 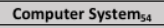 & $s_{54}$ & Yes & Yes & Yes & Yes \\
\hline & Computer System ${ }_{\text {ss }}$ & $S_{55}$ & Yes & Yes & Yes & Yes \\
\hline
\end{tabular}

The candidate computer systems in each of the library lists were also provided with additional measures (e.g., Capability Sustainment, Lifecycle Cost, and System Reliability). These measures were developed, maintained, and provided by the computer systems' owners to the SPaAS developer for further analysis (See Table 3).

TABLE III. COMPUTER SYSTEM MEASURES

\begin{tabular}{|c|c|c|c|c|c|}
\hline NCS Capability & $\begin{array}{c}\text { Candidate Computer } \\
\text { Systems }\end{array}$ & & $\begin{array}{c}\text { MTBF / } \\
\text { Hours }\end{array}$ & $\begin{array}{l}\text { Lifecycle } \\
\text { Cost / } \\
\text { Millions }\end{array}$ & $\begin{array}{l}\text { System } \\
\text { Reliability }\end{array}$ \\
\hline \multirow{5}{*}{$\begin{array}{l}\text { Joint-Coordinated Mission } \\
\text { Planning System Capability }\end{array}$} & Computer System $_{11}$ & $S_{11}$ & 11500 & 120 & 0.967186 \\
\hline & Computer System $_{12}$ & $S_{12}$ & 9382 & 90 & 0.827637 \\
\hline & Computer System $_{13}$ & $S_{13}$ & 10014 & 110 & 0.978186 \\
\hline & Computer System 14 & $S_{14}$ & 10856 & 135 & 0.993356 \\
\hline & Computer System $_{15}$ & $S_{15}$ & 10000 & 98 & 0.878186 \\
\hline \multirow{5}{*}{$\begin{array}{l}\text { Special Operations Mission } \\
\text { Analysis System Capability }\end{array}$} & Computer System $_{21}$ & $S_{21}$ & 9718 & 80 & 0.710678 \\
\hline & Computer System $_{22}$ & $S_{22}$ & 9519 & 75 & 0.800678 \\
\hline & Computer System $_{23}$ & $S_{23}$ & 8237 & 78 & 0.740646 \\
\hline & Computer System 24 & $S_{24}$ & 10225 & 104 & 0.877637 \\
\hline & Computer System $_{25}$ & $S_{25}$ & 7999 & 75 & 0.778186 \\
\hline \multirow{5}{*}{$\begin{array}{l}\text { Planning and Effects Based } \\
\text { System Capability }\end{array}$} & Computer System ${ }_{31}$ & $S_{31}$ & 11500 & 120 & 0.967186 \\
\hline & Computer System $_{32}$ & $S_{32}$ & 9382 & 90 & 0.827637 \\
\hline & Computer System $_{33}$ & $S_{33}$ & 10014 & 110 & 0.978186 \\
\hline & Computer System $_{34}$ & $S_{34}$ & 10737 & 129 & 0.983954 \\
\hline & Computer System $_{35}$ & $S_{35}$ & 7999 & 75 & 0.777169 \\
\hline \multirow{5}{*}{$\begin{array}{c}\text { Mission Modeling and } \\
\text { Simulation System Capability }\end{array}$} & Computer System S1 $_{41}$ & $S_{41}$ & 9718 & 80 & 0.710678 \\
\hline & Computer System $_{42}$ & $S_{42}$ & 9519 & 75 & 0.800678 \\
\hline & Computer System $_{43}$ & $S_{43}$ & 8237 & 78 & 0.740646 \\
\hline & Computer System 44 & $S_{44}$ & 8555 & 89 & 0.788195 \\
\hline & Computer System 45 & $S_{45}$ & 10304 & 115 & 0.922104 \\
\hline \multirow{5}{*}{$\begin{array}{l}\text { Joint Mission Planning Request } \\
\text { and Approval System Capability }\end{array}$} & Computer System $_{51}$ & $S_{51}$ & 11500 & 120 & 0.967186 \\
\hline & Computer System $_{\mathrm{s2}}$ & $S_{52}$ & 9382 & 90 & 0.827637 \\
\hline & Computer System $_{53}$ & $S_{53}$ & 10014 & 110 & 0.978186 \\
\hline & Computer System $_{54}$ & $S_{54}$ & 11982 & 113 & 0.977637 \\
\hline & Computer System $_{55}$ & $S_{55}$ & 8685 & 121 & 0.944186 \\
\hline
\end{tabular}

These measures were provided as part of the downselect process in choosing the computer system specifically for the SPaAS capability. In addition to the measurements provided by the computer system owners, the AHP offered the SPaAS developer flexibility in using their professional experience and subject matter expertise when determining the ranking priorities in selecting these computer systems based on the measures. The objective of the downselect process is to successfully satisfy a capability required by the SPaAS NCS. As part of the down select process, the MOE decision attributes (Systems Reliability, MTBF, Lifecycle Cost) were used to prioritize the computer system capability from each library list.
In determining the importance of each MOE decision attributes, the Analytical Hierarchy Process (AHP) was used to rank and prioritize the computer systems. The AHP approach provided the appropriate method in being able to tackle problems by breaking them down into a hierarchy of criteria and alternatives [10]. This process provided the basis for determining the critical MOE decision attributes using the attributes as the key factor in performing a pairwise comparison between computer systems [12]. In using each of the computer systems' measurements in the AHP, each system capability was prioritized based on the MOE decision attribute, with the top of the list being ranked as most important. In the case of this study, it was determined that systems reliability is the key factor specifically for the SPaAS solution.

For each of the SPaAS capability library lists, the AHP produced a ranking order that was categorized using each of the decision attributes. This process resulted in each of the library lists having different rankings based on the decision attribute priorities. Doing so provided a list that could be used in making a well-informed decision based on the importance of the decision attributes. Since this study focused primarily on mission success of a combined computer system's capabilities, the solution focused on using the system reliability decision attribute for each library list to determine the SPaAS solution. Table 4 was produced by prioritizing and using the systems reliability measures which determined the computer systems that were required in order to be able to accomplish the mission successfully.

TABLE IV. SPaAS PREFERRED NCS

\begin{tabular}{|c|c|c|c|c|c|}
\hline NCS Capability & $\begin{array}{l}\text { Candidate Computer } \\
\text { Systems }\end{array}$ & & $\begin{array}{c}\text { MTBF/ } \\
\text { Hours }\end{array}$ & $\begin{array}{l}\text { Uifecycle } \\
\text { Cost/ } \\
\text { Mallions }\end{array}$ & $\begin{array}{c}\text { System } \\
\text { Reliability }\end{array}$ \\
\hline Joint-Coordinated Mission Planning System Capability & Computer System $_{24}$ & $\mathbf{s}_{34}$ & 10856 & 135 & 0.993356 \\
\hline Special Operations Mission Analysis System Capability & Computer System ${ }_{24}$ & $\mathbf{s}_{34}$ & 10225 & 104 & 0.877637 \\
\hline Planning and Effects Based System Capability & Computer Systemp & $\mathbf{s}_{\mu}$ & 10737 & 129 & 0.983954 \\
\hline Mission Modeling and Simulation System Capability & Computer Systemys & $\mathbf{s}_{86}$ & 10304 & 115 & 0.842104 \\
\hline Joint Mission Pla & Computer System, & $\mathbf{s}_{3}$ & 10014 & 110 & 0.978186 \\
\hline
\end{tabular}

The SPaAS solution was developed by aligning SPaAS capabilities with computer systems requirements that produced an initial set of candidate systems. The initial set of candidate systems was also processed through the workflow in refining the library lists using additional decision attributes (i.e., System Capability Availability, Capability Readiness, Acquisition Time, Acquisition Cost). The result was a product with a finalized set of library lists for each of the SPaAS capabilities. Each library list was processed through the AHP in determining the ranking order categorized by the MOE model, including Systems Reliability, Lifecycle Cost, and Capability Sustainment. Based on the ranked library lists, a SPaAS solution was produced and was analyzed further in improving the SPaAS solution based on tradeoffs associated with the decision attributes of mission reliability, capability sustainment, and lifecycle cost.

\section{FUTURE RELATED WORK}

The NCS solution and the estimated decision attributes will be further analyzed in order to determine the MOE. The previous section determines the decision attributes based on a quantitative approach for measuring the attributes considered to be critical components of the MOE of the NCS. The 
question is how to balance all the decision attributes calculated to be considered of importance to determine a specific measure in determining the MOE of the NCS solution. This approach will evolve into a notional conceptual methodology based on on specific decision attributes to select computer systems and calculate the effective measures of the NCS. The methodology will consider a process that is able to calculate these decision attributes based on weighted priorities. The weighted priorities take in for account the importance of each of the decision attributes and considers prioritization of each of the attributes based on historical information and experiences of the decision stakeholders. Further research is required in this area in order to determine the best approach in determining the feasibility of the NCS solution based on the decision attributes considered.

\section{CONCLUSION}

The continued work being performed in this area will provide a well-defined methodology in which an acquisition program can utilize a decision process to determine the best feasible approach for satisfying an emerging capability. The approach hinges on the utilization of current operational or developmental systems to fulfill user requirements by taking advantage of existing systems. This paper defined an approach to explore the selection of systems when combined can provide a means to satisfy an emerging capability by minimizing the number of systems for development and utilizing current operational system capabilities that are fielded.

In future work as part of the selection process, the NCS solution will be verified and validated by attaining a measurable metric based on selected decision attributes in determining the NCS effectiveness. The measurement for the NCS effectiveness will provide information to determine if investment in developing the NCS solution can be a viable commitment to successfully satisfy the operational requirement for the users. There are continued work to be performed in this area, however, this paper allows us to review a notional approach in identifying decision attributes and using them as part of a process to identify a NCS solution for consideration. This will be a continued effort in the area of effectiveness measure in identifying and quantifying the preferred NCS solution in satisfying an operational requirement. This paper will be followed with a detailed methodology, effectiveness models, and application that will be applied towards a NCS solution to be considered and addressed.

\section{REFERENCES}

[1] Defense, D. o., "Defense acquisition guidebook," in Defense Acquisition Guidebook, ed, 2013.

[2] Defense, D. o., "Reliability Program for Systems and Equipment Development and Production," vol. MIL-STD-785B, D. o. Defense, Ed., ed. Washington, DC: Department of Defense, 1980.

[3] Defense, O. o. t. S. o., "Operating and Support Cost-Estimation Guide," O. o. t. S. o. Defense, Ed., ed. Washington, DC: Cost Assessment and Program Evaluation (CAPE), 2014.

[4] Eiband, M., Eveleigh, T., Holzer, T., and Sarkani, S., "Reusing DoD Legacy Systems: Making the Right Choice," Defense Acquisition Research Journal, vol. 20, pp. 154-173, 2013.

[5] Friedman, M. A., Tran, P. Y., and Goddard, P. I., "Hardware/Software System Reliability Modeling," in Reliability of Software Intensive Systems (Advanced Computing and Telecommunications Series), 1st Edition ed: William Andrew, 1995.

[6] Jaynes, R. A. S. C., Simpson, T., Mallicoat, D., Francisco, J., Mizell, W., and Cikovic, D., "Managing O\&S Costs - A Framework to Consider," 2012.

[7] NASAR. (2016, October 10). National Association for Search and Rescue. Available: http://www.nasar.org/

[8] Office, U. S. G. A., "GAO Cost Estimating and Assessment Guide," GAO-09-3SP ed: GAO, 2009.

[9] Peterson, L. L. and Davie, B. S., Computer Networks, 1st ed. San Francisco,Calif.: Morgan Kaufmann, 2000.

[10] Saaty, T. L., "Priority setting in complex problems," IEEE Transactions on Engineering Management, vol. EM-30, pp. 140-155, 1983.

[11] Under Secretary of Defense for Acquisition, T. a. L., or USD(AT\&L), "Operation of the Defense Acquisition System 5000.02," vol. 5000.02, U. A. L. Department of Defense, Ed., ed. Washington, DC, 2015.

[12] Wauthier, F. L., Jordan, M. I., and Jojic, N., "Efficient Ranking from Pairwise Comparisons," in The 30th International Conference on Machine Learning, 2013. 